
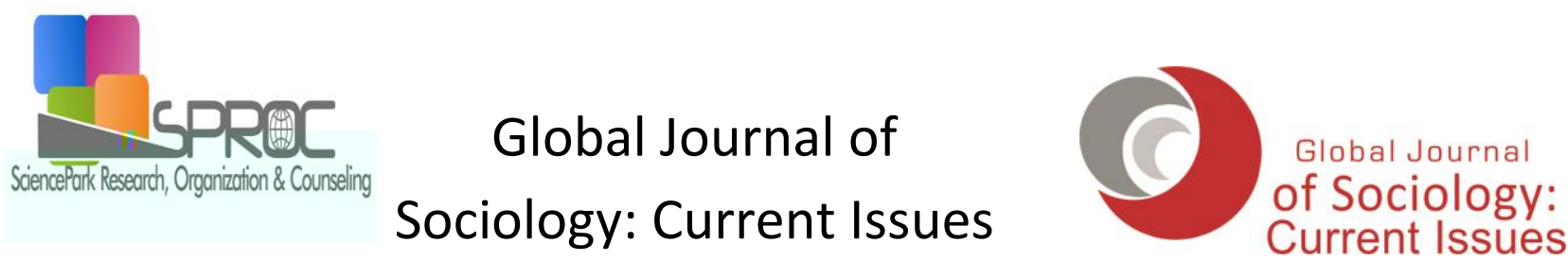

Volume 07, Issue 1, (2017) 9-18

www.gjsoc.eu

\title{
Deindustrialization, insecurity and demise of night economy: Retrospection on Nigerian underdevelopment
}

Elijah Babasola Afolabi Agbaje*, Department of Political Sciences, Faculty of The Social Sciences, College of Management and Social Sciences, Osun State University, Osogbo, Nigeria

\section{Suggested Citation}

Agbaje, E.B.A. (2017). Deindustrialization, insecurity and demise of night economy: Retrospection on Nigerian underdevelopment. $\quad P \quad c k \quad c k \quad(1), 9-18$.

Received November 27, 2016; revised January 2, 2017; accepted April 17, 2017.

Selection and peer review under responsibility of Mustafa Gunduz, Cukurova University, Turkey.

C2016 SciencePark Research, Organization \& Counseling. All rights reserved.

\begin{abstract}
Nigerian faces complex and mounting challenges of underdevelopment. However, this challenge could not have been so intimidating if negative socioeconomic, political and technological forces have also not combined to ensure the demise of her once bolstering 'night economy'. Contrary to the experience in the 70s when Nigerians worked and were moving 24 hours daily, the crowding out of 'night economy' and the growing culture of idleness have combined to dealt a great blow to the chances of Nigerian becoming a comparatively developed nation as some of the Asian tigers. With a retrospective case study of what then used to be Ikeja Industrial Estate, the two most destructive forces that have combined to retard Nigeria's progress are the trajectories of deindustrialization and demise of night economy both of which are serendipities of economic policy summersault that happened in the mid-80, to which subsequent heightened prevalence of insecurity have added the nodal norm of near complete social disorder. This paper, being product intuitive personal insights and area-specific field observation, argues that the only way to rapidly move Nigeria out of the doldrums of pervasive underdevelopment is to fast-track Nigerians back to work starting with rapid and massive facilitation of primary productive engagement. Towards achieving this, it recommends that government must simultaneously adopt pragmatic economic strategies of fiscal discipline, conspicuous interventionist posture to accelerate aggressive diversification, reindustrialization, state-enforced import substitution, selective outward orientation, and revival of her demised night economy.
\end{abstract}

Keywords: Deindustralization, night economy, Nigeria.

*ADDRESS FOR CORRESPONDENCE: Elijah Babasola Afolabi Agbaje, Department of Political Sciences, Faculty of The Social Sciences,College of Management and Social Sciences, Osun State University, Osogbo, Nigeria ck : ebagbaje@yahoo.com / Tel no: +234-805-591-8422 
Agbaje, E.B.A. (2017). Deindustrialization, insecurity and demise of night economy: Retrospection on Nigerian underdevelopment. $P \quad c k \quad c k \quad(1), 9-18$.

\section{Introduction}

The hope of Nigeria ever rapidly getting developed looks dimmer as each day breaks. Despite all the efforts made and still being made by citizens and government, it is as if pervasive underdevelopment has become an enduring reality that Nigeria must live with. Almost all known paradigms of economic transformation have been adopted by different politico-economic regimes with the result that Nigeria and Nigerians progressively remains pervasively poor (Ojo, 1987; Okonjo-Iweala, 2005; Olurode, 2005, Guardian, 2009; Upreti, 2015). The reason Nigeria has been, and for which it may remain very poor is, simply stated, no other than the pervasively low rate of production and growing culture of idleness and helplessness. But, simple as it appears, the challenge is much more complex. This challenge is in itself a symptom of some other variables, which include drastic deindustrialization and increasing rate of social insecurity among others. As if Nigeria was preparing for her socioeconomic funeral, the adoption of SAP in mid-80s ensured that all her channels of productivity and livelihood went comatose at the dawn of $90 \mathrm{~s}$, thus breeding the ills of joblessness and rising spate of insecurity.

In the 70s, ranging from transport to trade and commerce, from manufacturing to hospitality and leisure, the profile of night economy was on the rise as increasing numbers of Nigerians have the opportunity of embarking on one job or the other to legitimately earn their living at any time of the 24 hours of the day. Then, one can say without any fear of contradiction that Nigeria was working 24 hours per day. But for the advent of ahistorical corrupt order that carelessly embarked upon structural adjustment, almost every Nigerians, in one way or the other, productively contribute to the then growing wealth of the nation while mass starvation was never an issue of great concern as it now seems. It then can be stated that the single most destructive factor that dragged Nigerian to the bottom-pit of development was the advent of poorly conceived policies that reversed the growing industrialization of the Nigerian economy. With deindustrialization as a modal cause, the resultant challenges of joblessness and insecurity have now combined to ensure the total collapse of her once bolstering and growthigniting night economy (Lovatt 1996). As it is today, Nigerians that were once working 24 hours a day, except in the area of leisure, media and entertainment, rarely works beyond 8 hours. Nigeria, that once function all round the 24 hours in a day, now have all activities concentrated within one-third of the available hours, that is, between $8 \mathrm{am}$ to $4 \mathrm{pm}$, with all its attendant congestions, obstacles or obstructions that has encouraged growing culture of idleness.

Following an area-specific field observation driven by intuitive logic around one of hitherto, key industrial estates (Ikeja) Lagos, in Nigeria, this paper in a retrospective analysis of Nigerian underdevelopment posits that unless drastic steps are taken to reverse deindustrialization and demise of night economy, the hope of Nigeria ever getting develop as fast as possible to outpace the population growth and poverty rate will forever remain a mirage. As these contradictions increases in Nigeria and other sub-Saharan African countries, the entire sub-region and the globe will in one way or the other continue to feel the impact either as influx of desperate migrants or through increasing global spread of nefarious activities. The only way out therefore is a political regime that reflects high dose of fiscal discipline, and capable of engendering institutional reform that will reprofile the state and its ancillaries. This require conspicuous interventionist posture to accelerate aggressive diversification, reindustrialization, state-enforced import substitution, selective outward orientation, and revival of her demised night economy. It is hoped that the Buhari administration holds some promise in this regard if not derailed.

\section{Conceptual analysis}

While countries in East Asia are, through domestic demand and rising local production, increasingly growing their economy out of poverty, (Kubota 2016), development remains a hard-knot for Nigeria and most sub-Saharan African nations as they daily freely falls into the pit of pervasive underdevelopment 
Agbaje, E.B.A. (2017). Deindustrialization, insecurity and demise of night economy: Retrospection on Nigerian underdevelopment.

$$
P \quad \text { ck ck (1), 9-18. }
$$

and poverty. Different paradigms such as deregulation, privatization, commercialization, concessions, private-public partnership, management/service contracting, have been adopted across most troubled

regions with the plights of citizens and governments growing worse. The missing links of these efforts has been traced to low productivity arising from low industrialization, pervasive culture of idleness, corruption and free access to dirty money in some of the developing countries (Ruccio, 2008). Added to this, to complete the deindustrialization circle, has been the challenges of insecurity and consequent collapse of night economy. BCk simply connotes the collapse of industrial activity. Industrialization has been defined as a process through which a society transforms itself (Haferkamp \& Smelser, 1992) from agrarian economy to become a manufacturing or industrial community, deploying modern scientific, human and technological competences towards attainment of mass production of goods and services (Sheffrin, 2003; Haferkamp \& Smelser, 1992). It is characterized by innovative optimum investment of time and resources as against superstitious approach to wealth creation. Whether developed or developing, the industrial sector remains a critical aspect of a nation's economy. Right from the first transformation from agrarian to an industrial economy in the mid- $18^{\text {th }}$ through early $19^{\text {th }}$ century, which simultaneously took place in Europe and America spreading from Britain to Belgium, Germany and France, the world of productivity has moved beyond human imagination. This received an added boost from the second phase of industrial transformation that came about around mid- $19^{\text {th }}$ century with further refinement of steam engine, the invention of internal combustion engines, the harnessing of electricity, the construction of canals, railways and electricity power lines (Buchanan 2016). The invention of assembly line shortly therefore completes the transformation. Ever since then, only nations that are doomed to remain world underdog neglects industrialization and its adjoint scientific exploration. By the end of the $20^{\text {th }}$ century, Asia had tapped into industrial progress, leaving behind majority of Africa. Industrialization brings with it a whole lot of goods such as employment opportunities, appropriate and adequate utilization of all types of resources, promotion of education, training and research, increased productivity of labour as well as balanced regional development.

Industrialization is never attained by chance. It is a the system of transformation in production that results from steady development, study and use of scientific knowledge characterized by division of labour, increasing specialization and use of mechanical, chemical and power-driven as well as organizational and intellectual aids to produce goods and services. It is therefore ahistorical to expect a nation to develop without strong inclination towards scientific exploration and initiation of industrial activities that gestate from agriculture and spans creative development of cottage activities, manufacturing, mining and mineral processing, local distribution and export of manufactured goods. It is regrettable that due to economic and fiscal impropriety, the structural change that often lead to rapid industrialization in other regions and nations of the world carelessly led Nigeria into a state of vast deindustrialization and underdevelopment. This gave rise to a situation in which over $73.4 \mathrm{million}$ of the nation's population who are mostly youth were unemployed in year 2013. Vanguard Online reported on May 14, 2014 that 60million Nigerians were unemployed just as World Bank in 2010 puts poverty rate among Nigerians to be about 46 percent of the country's population (see also World Bank 2012). Many of these idle minds are already becoming production platform and their hands increasingly becoming production appliances of the devil.

$L \quad \quad \quad c k \quad$ : Intellectual curiosity about the idea of night economy sprang up in Britain in early 1990s (Lovatt, 1994). The concept of night economy is easily associated with leisure or night recreational activities (Hadfield, 2011). Though this seems ever valid across time and climes, night economy does offer greater impetus for national growth and development. Literature on night-time economy is extensive and features great heterogeneity in study design and purpose, outcome measure, and treatment of the data. Scope of research and its findings have been known to be greatly influenced by contextual and jurisdictional issues pertaining to the identification of pertinent research questions and the divergent cultural and situational factors one encounters across different countries, regions, cities, neighbourhoods and social scenes (Hadfield, 2009). Beyond its social inclination, night economy has ever been part of industrial and rural economy. From Jane Jacobs's analyses of the social and economic benefits of night economy, after-dark street economic attractions have been important theoretical 
Agbaje, E.B.A. (2017). Deindustrialization, insecurity and demise of night economy: Retrospection on Nigerian underdevelopment.

$$
P \quad c k \quad c k \quad(1), 9-18 \text {. }
$$

cornerstone of the '24-hour city' concept and also of official planning policy guidance in the UK (Jacobs, 1961). It is seen as a veritable avenue for extending the business day (Thomas \& Bromley, 2000). In recent years, the political vision of many municipal governments across the world has crystallized

around ambitious plans to create the '24-hour city,' an urban core populated by residents, workers and visitors around the clock (see Heath 1997; and Heath and Stickland, 1997; Jones, Hillier \& Turner, 1999). Specifically, as part of strategies for enhancing national productivity, 40 percent of Americans reportedly work at night, weekend and rotating shifts. In the United Arabs Emirates, night economy contributes hours of productive services across its arrays of mega malls, array of leisure, training and vocational schools, fashion making, health and beauty outfits and services that makes Dubai a tourist haven of the global community. Besides, night economy provide greater avenue for safe night movement of people from one end of a country and the world to another. It allows for maximum use of non-renewable factors of production such as time and other resources. It is reported that Dutch capital, Amsterdam deemed the night economy so critical that it has a Night Mayor who oversees the activity of the city at night. In United Kingdom, about 1.3milliion people whose economic activities contributes well over $66 \mathrm{~m}$ Pound Sterling per annum are said to be engaged solely on night economic activities. Going by Hadfield (2011), the diversity and number of these various commercial activities underlines Sydney's status as a major global city. It demonstrates that the extent of visitor engagement and demand generated by a large local and regional population are such as to create many social, economic and cultural opportunities not available to local government in smaller towns and cities. At the same time, the extent of activity in the NTE has generate the need for major efforts by government to ensure effective management and service provision in areas of urban planning, design and infrastructure, policing, regulation, enforcement and health care.

The'24 Hour City' Vision (Heath, 1997) is conceived as a period of added economic freedoms; a period to extend one's ability to derive greater self-satisfaction and benefits. While on one hand, it is believed that:

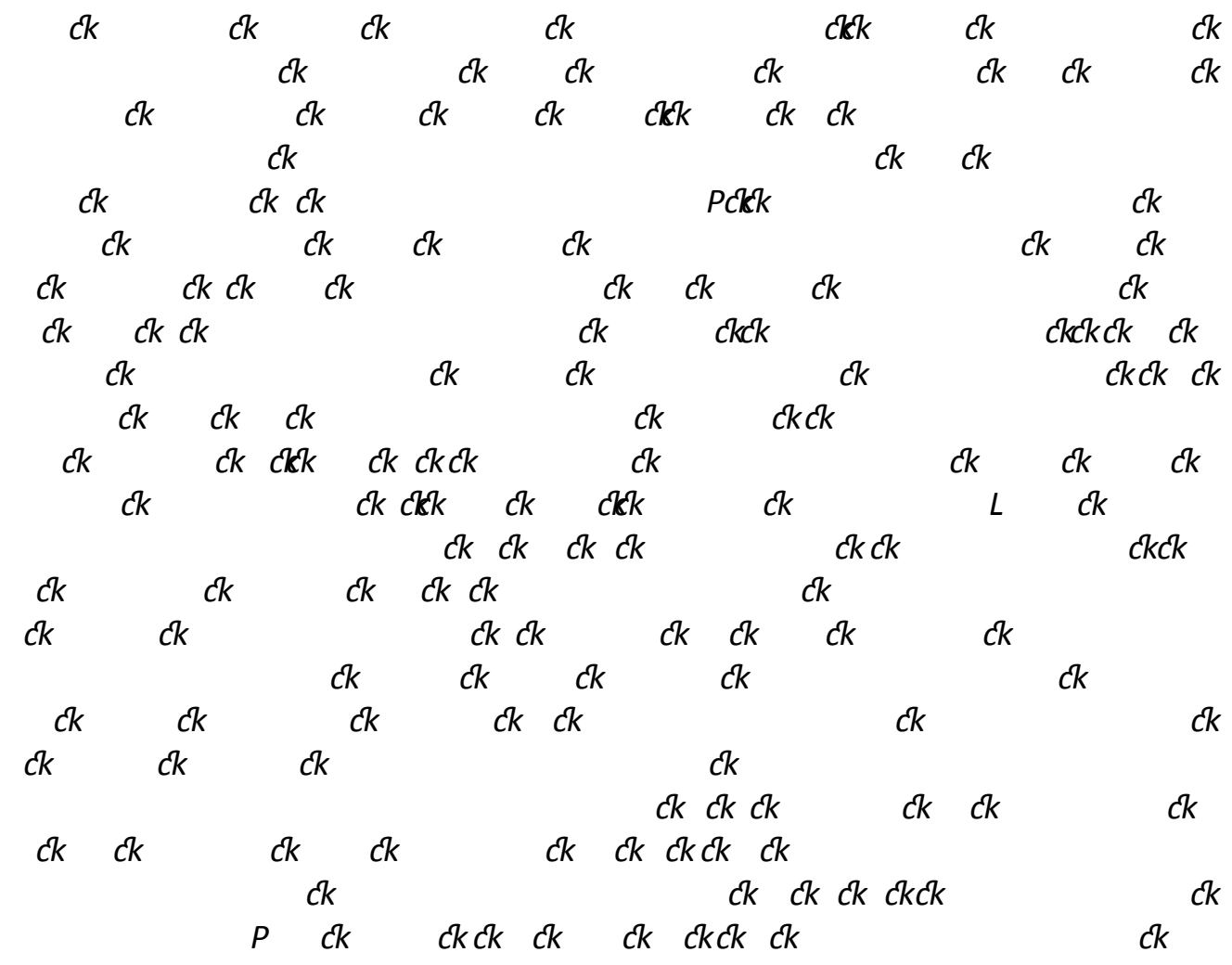


Agbaje, E.B.A. (2017). Deindustrialization, insecurity and demise of night economy: Retrospection on Nigerian underdevelopment.

$P \quad$ ck ck (1), 9-18.

$\begin{array}{ccccccc}c k & c k & & c k c k & c k & c k & c k \\ c k c k & c k & c k & P & c k & \end{array}$

\section{Brief historiography of night economy and growing culture of poverty and underdevelopment in Nigeria}

Even within the traditional system, night economy was part and parcel of human life. Hunters and diviners made much of their living through night activities. Traders and travelers travel all through night to and fro different destinations in pursuance of commerce. The period, 1970s-1980s represent the peak age of night economic activities in Nigeria. People buy and sell at night, transporters and haulage companies works at night. Very importantly, Nigerian Railway Corporation operates all through the 24 hours of the day, with people moving in and out of railway stations that are scattered across the county. As factories are opened 24 hours, associated services such as transport, catering, health, security, vendors and nearby residents and traders engage in one form of product or service provision thereby making their earning all through the entire hours in the day. Most traders between 70s and 80s enjoy travelling at night to and fro the source of their merchandize. Notable among these traders are sellers of household items such as clothes, edibles, consumables and those who deal in agricultural merchandize. Those who engage in factory supplies also travel all night to get to their destinations, with loading and off-loading occurring 24 hours of the day. Because of 24-hour daylong activities, filling stations, canteens, and other critical services are rendered day and nights. Keen observers of Nigerian economic flora of the early to late 70 s will most probably conjectured that Nigeria was on set to attain economic and industrial greatness in not too distant a future.

However, with a retrospection on the then thriving Ikeja industrial estate, one of the modest models of industrial transformation efforts in African third world nations in the 70s, in comparison with the level of industrial activity in Nigeria today, one can firmly state that the story has changed for the worse.

$$
c k \quad c k \quad c k \quad L \quad c k \quad c k \quad c k \quad c k c k \quad c k
$$

Going by ILO convention, the eight-hour day implying 48 hours per week was a key demand of the working class all over the world. To the workers, the extension and generalized application of the 8 hour per day represented a reform which no other can equal in value. Workers, generally see this as a chance to share in the distribution of the new wealth created by the modern industry and to receive that share in the form of spare time. However, if not more, every citizen that are of productive age should share this productive experience. While it is usual and normal to regard normal working hours as daylight time, night economy, provides opportunity for shift workers to make their contribution to national growth and development, by working beyond $6 \mathrm{pm}$ into around $10 \mathrm{pm}$, and some other workers resuming work at $10 \mathrm{pm}$ to close at $6 \mathrm{am}$. What therefore constitute a resting period for some, to others represent hours of productive engagement. A nation in need of accelerated development cannot afford to allow critical factors of production to lie idle for most part of the 24-hour day, while some are resting, other unemployed individuals can make effective use of the same resources from which those resting have just taken their time off. This generally will lead to the development of the nation that promotes such productive framework. In Nigeria and the rest of the world, the shift worker of 30-50 years ago was likely to be factory based. Shift work is an employment practiced, designed to make use of, or provide service across all 24 hours of the clock each day of the week (often abbreviated as 24/7). The practice typically sees the day divided into at least three segments or shifts, or periods of time during which different groups of workers in rotation perform their duties. While it also could breed a number of obstacles for social and national development if not well managed, advantages associated with night 
Agbaje, E.B.A. (2017). Deindustrialization, insecurity and demise of night economy: Retrospection on Nigerian underdevelopment.

$$
P \quad c k \text { ck (1), 9-18. }
$$

economy for nations in urgent need of development is endless. It is a means of providing massive employment.

From empirical realities, it has been established that both rapidly industrializing and even the lessindustrialized ones have need for embarking on policies aimed at making clean water, universal primary health, universal primary education among others available. In Nigeria, like many other sub-Saharan African countries, national poverty has rendered attainment of many of these facilities an impossible task. Hence, it could be argued that Nigeria, due to critical industrial underdevelopment is, in the midst

of great potentials for national prosperity, still ridden with pervasive poverty across all these basic indexes of decent living. Without increased productivity that can only be made possible through aggressive industrialization and immediate reinvigoration of night economy, this feat cannot be achieved. Just as critical shortfall in human capital competencies have led to creation of inefficient local industries that are unable to compete in the global market, it is equal a fact that these competencies can only be developed through meaningful productive life available only by the same industrial development. It is this type of engagement that permits the chances of overcoming low human capital development, social poverty and over-reliance on foreign supplies. It is through this that nations, such as Nigeria, desirous of accelerated development will discover how to avoid inappropriate adoption and mixing of technologies, and thereby create the needed synergy between industrialization, employment and poverty reduction. Industrial productivity remains the sine-qua-non for national prosperity. The result of a disconnect remains that more than 40 percent of world working populace are referred to as "working poor" whose income falls below \$2 per day and therefore unable to keep themselves and family out of the poverty line (see International Fund for Agricultural Development, 2010). If this is the situation, even in regions where industrialization has taken place, one can only imagine what happens in regions or nations where there is apparent absence of meaning industrial or productive activity. To resolve the debate on the nexus between industrialization, night economy and development, in all of the equations or synergies, the relationship is mutually reinforcing. Night economy enhances industrialization, industrialization enhances night economy and both are necessary conditions for national prosperity. This move is needed to move over 60 million idling Nigerian youth back into the productive path.

While Marxian theory posits that "it is the very nature of the capitalist mode of production to overwork some of the workers while reaping the rest as reserve army of unemployed paupers" (Ferencak, Stanisic, Radisic \& Robromirov, 2011); that capitalism, with its constant instability, is strongly embedded with pervasive unemployment, it has been overly established that lack of industrialization does greater evil as resources are scarcely used, time and factors of production rendered useless and man most frustrated. For nations such as Nigeria, industrialization and advantages associated with increased productivity availed by night economy is a sure path to averting the ever-growing pervasive underdevelopment and poverty (Heath \& Stickland, 1997). No doubt any effort directed towards industrialization and reintroduction of night economy for Nigeria will be a step in the right direction. It is one sure way of diversifying the ailing national economy. Resources will be better used, more people will be engaged, more time will be devoted to production, and national wealth will increase. This will span through almost every segment of national life.

$c k \quad c k \quad c k \quad c k$

Arising from its being the site of convergence of economic and productive activities, Ikeja industrial estate was always a beehive of economic activities all through the 24 hours of the day with workers regularly moving in and out, and lorries and buses, engaging several thousands of young and old loading and discharging goods and commuters for the most part of the 24 hours of the day. To underscore the importance of this estate, there was an extension of rail service into it to cater for bulk movement of goods and products. Apart from these formal business activities, the budging economic network availed by the Estate, provided flourishing business opportunities for petty and small scale businessmen and 
Agbaje, E.B.A. (2017). Deindustrialization, insecurity and demise of night economy: Retrospection on Nigerian underdevelopment.

$$
P \quad \text { ck ck (1), 9-18. }
$$

women, who, in some cases for the whole of the 24 hours of the day, carry on their businesses to meet the immediate needs of the workers in and out of factories day and night. This include haulage companies, catering services, security outfits, and transport shuttles to all the routes in Lagos, with Lagos State Transport Corporation running regular shuttles from the then $2^{\text {nd }}$ Gate to as far as Race Course in Lagos Island and other areas of Lagos metro 
Agbaje, E.B.A. (2017). Deindustrialization, insecurity and demise of night economy: Retrospection on Nigerian underdevelopment.

$$
P \quad c k \quad c k \quad(1), 9-18 \text {. }
$$

banks and financiers must be more patriotic; citizens must be better trained and society made better secured. Achieving all of these calls for a regime that is fiscally disciplined, efficient, markedly developmental and having high dose of economic nationalism.

President Muhammadu Buhari assumed office as Nigerian president a little over a year ago on a wave of optimism that the ex-military ruler could revive the nation battled by failing oil price and decades of corruption; maladministration, diversion and embezzlement of public fund meant for development of the economy, gross under-provision and poor maintenance of infrastructural facilities and basic amenities necessary to better the lives of the citizens. With combination of past wastages and unfolding recurrence of sabotaging events and moves, Africa's biggest economy is now on its kneel. Charting the way forward for Nigeria must, therefore, necessarily take holistic account of what has befell the nation

that warrants her present state of underdevelopment. This no doubt has been traced to reckless deindustrialization, insecurity, total collapse of night economy and reckless avenues that the state has provided the elites to reproduce themselves in response to survival instinct propelled by a failing state system. Based on logically grounded intuitive insights and field observation adopted by this research, to move the nation forward, certain steps, some of which are profiled hereunder, must be embarked upon by the government with active cooperation of the citizens.

- First, both government and citizens must realize that creating a safe, vibrant and well-balanced economy, particularly the one that operates in the night, is a challenge, but it holds amazing growth potential. This is the reason nations and governments at all levels across the globe are finding unique and innovative ways towards creating thriving and safer night economy (Local Government Association, 2012). All that it calls for is establishment of procedural, security, legal and infrastructural frameworks to allow shops, factories and other business to operate at night. Key to this aspiration is equipping law enforcement agents to provide adequate security which also has the double advantage of safeguarding economic interest and increasing job expansion for security personnel. Provision of CCTV which also is human invented and human-monitored will enhance security, prevent losses associated with insecurity and also provide jobs.

- Second, it should be realized that the Nigerian government has consistently failed to appreciate the synergy between human capital development, research and industrialization. Rather than develop many of the innovative ideas generated by ever resourceful Nigerians, those in government mostly concern themselves with what they can amass only after spending so little or nothing to genuinely promote the developmental interest and aspiration of the nation. After all, making such money available for national development, to them, means depriving them of the opportunity to successfully embark on massive looting that makes them stay afloat of other 'ordinary Nigerians'. Effort should be directed at combating corruption. Any outcry against such move remains deliberate antics of the corrupt elite to keep Nigerians in perpetual servitude. These loots must be recovered and redirected towards technological adaptation and financing ideas generated by innovative young Nigerians. The need to un-lock the nation's human and material growth potential is now; there can be no better time.

Three, it is to be noted that the greatest beneficiaries of night economy will be government and factories owners. Equipment, which life span has been programmed not to last more than a specific period of time (whether used or not) will not lie idle at any time during its useful life period. Production fluctuations arising from too much demand on national electricity grip at particular concentrated hours of the day will be reduced as production activities will be spread to part of the night when demand is low. At any rate, greater usage means lesser cost just as increased productivity means more tax revenue for the government. Also, night economy offers the opportunity to reduce much of the congestions that cogs daytime business and productive 
Agbaje, E.B.A. (2017). Deindustrialization, insecurity and demise of night economy: Retrospection on Nigerian underdevelopment. $P \quad$ ck ck (1), 9-18.

activities (Badger, 2013). As added advantage, many of the activities such as refuse collection, road mending, security mapping, courier distribution, etc that are performed by government and major organizations which are added obstruction in daytime can be safely and better carried out at night.

- Four, it is often argued that industrialization and night economy are both prone to vices. It is also true that if well managed, industrialization and effective utilization of night economy (see Thomas and Bromley, R. 2000) remains the basis for addressing almost all of the social vices that currently bedeviled the Nigerian economy. It provides jobs, increase market for local and agricultural products as raw materials, provide business opportunities for millions of ancillary trades and commerce as SMEs. Also, though, it is argued that industrialization creates army of

reserved workers, who may be unemployed as machines replaces human labour, yet, there is only an insignificant few that can be gainfully employed in an environment where resources are primitively explored, primitively processed and primitively consumed. Industrialization opens up a vast array of increased opportunities for people and nations to assert their ideas towards changing their fortune for better. Industrialization and night economy has the potential to reduce crimes and other social vices (such as stealing, robbery, prostitution and even terrorism) since virtually every persons will have something doing and will be less tempted to join bad trains.

- Five, through introduction of night economy, the army of resourceful but jobless youth can be incorporated into the formal economic set-up through creation of flexible working hours that allow advantageous combination of training and working. In the 70s, people work and attend evening classes and correspondence programmes to update their skill. One can quickly remember the exploits and efficacy of $\quad P \quad c k$ a Nigerian based correspondence college in this regard. Increased national productivity that results from this marriage of knowledge and labour will reduce dependency on foreign goods and services thereby reducing that portion of national earnings committed to external sourcing of goods and services, while millions of Nigerian citizens that can produce these goods and services remained unemployed.

- Six, in this period when the economy fortune of the nation is rapidly nose-diving and reliance on oil as the mainstay of the economy largely threatened, policy makers and planners needs to give thought to appropriate measures that could tap into the use of idle resources to boost the economy of the country. For instance, rather than concentrate all haulage and movement on daytime, increase in security-personnel and facilities- will encourage night movements and commerce. This will turn out a win-win addition to addressing the Nigerian unemployment problem; more security personnel will be employed just as more people will freely engage in economic activities all through $24 / 7$, thereby increasing the base of government tax revenue.

- Finally, industrialization and shift work provides women with the opportunity to work on flexible hours. This, rather than baby-sit them allowed them to make critical contribution to the upkeep of the family thereby reducing family crisis and tensions. Notwithstanding the risks (Thomas and Bromley 2000) posed by night economy, the advantages are tremendous and can only be neglected by nations that are to be perpetually doomed as world underdogs.

\section{Conclusion}

The paper examined the nexus between industrialization, night economy and national development and prosperity for nations that are locked in the dark theatre of pervasive poverty and underdevelopment. With hindsight of Ikeja Industrial Estate, it argues that there can be no better way of returning Nigeria back to the path of development than pursuing aggressive 
Agbaje, E.B.A. (2017). Deindustrialization, insecurity and demise of night economy: Retrospection on Nigerian underdevelopment.

$$
P \quad \text { ck ck (1), 9-18. }
$$

policies of reindustrialization that will avail Nigerians to once more witness the endless opportunities afforded through 24-hour night economy. With this, much of the idling Nigerian youths, many of who are currently pursuing inglorious activities across the nation and the globe will be redirected towards productive and meaningful life. With appropriate policies and proper management, once this basic challenge is resolved every other issues associated with industrialization and night economy will only end up creating added opportunities for more jobs, more services, increased government revenue and national prosperity. 
Agbaje, E.B.A. (2017). Deindustrialization, insecurity and demise of night economy: Retrospection on Nigerian underdevelopment.
$P$
ck $\quad c k \quad(1), 9-18$.

\section{References}

Badger, E. (2013) How Traffic Congestion Affects Economic Growth: For good and bad,

Oct 22. Retrieved from; http://www.citylab.com/commute/2013/10/how-traffic-congestion-impacts-economic-growth/7310/

Buchanan, R.A. (2016) History of technology, . Retrieved from; https://www.britannica.com/technology/history-of-technology/The-Industrial-Revolution-1750-1900 accessed 26 Aug 2016.

Ferencak, M., Stanisic, I., M., \& Radisic, D. R.(2011) Levels of frictional unemployment in the Serbia, in: $\quad c k c k$ $P \quad c k \quad P c k \quad c k c k c k \quad c k \quad$ Nk Novi Sad, Serbi, September 14-

16. 537-541.

Greater London Authority (GLA) (2002) ckL ck ckL in association with CASA and Dr Andy Lovatt, commissioned by the Greater London Authority, the London Development Agency and Transport for London. SDS Technical Report Six, June, London: GLA.

Hadfield, P. (2011).L $\quad c k c k \quad c k \quad c k c k \quad c k$ A Review for the City of Sydney, September. 39.

Haferkamp, H., \& Smelser, N. J. (1992). Social change and modernity. Berkeley: University of California press.

Heath, T. (1997) 'The Twenty-Four Hour City Concept - A Review of Initiatives in British Cities,'

$B C k \quad, \quad(2), 193-204$.

Heath, T., \& Stickland, R. (1997) 'The Twenty-Four Hour City Concept,' in T. Oc and S. Tiesdell (eds.) $P \quad c k$ $c k \quad c k \quad c k \quad c k \quad c k$, London: Paul Chapman Publishing.

Jacobs, J. (1961) ckBck $\quad c k \quad c k \quad c k \quad c k$, Harmondsworth: Penguin Jones, P., Hillier, D., \& Turner, D. (1999) ‘ $\quad c k$ 68, May: 164-165.

International Fund for Agricultural Development (2010), $\quad$ ～$\quad$ : New realities, new challenges: new opportunities for tomorrow's generation. Rome: IFAD.

Kubota, K. (2016) East Asia and Pacific remains bright spot in difficult global landscape, World Bank. Retrieved from; http://www.worldbank.org/en/news/press-release/2012/12/19/east-asia-pacific-remains-bright-spotdifficult-global-landscape

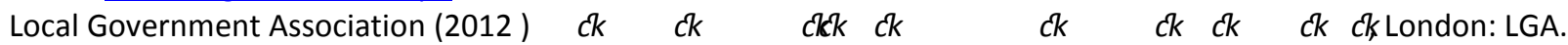

Lovatt, A. (1996) 'The Ecstasy of Urban Regeneration: Regulation of the Night-time Economy in the Transition to a Post-Fordist City,' in J. O' Connor and D. Wynne (eds.) $\quad c k \quad c k c k \quad c k$

$$
\text { ck , Aldershot: Arena. }
$$

Lovatt, A., O’Connor, J., Montgomery, J., \& Owens, P.(1994) ck $\quad$ Pckck ck $\quad c k \quad c k$ $L \quad c k c k \quad c k \quad c k \quad$ L Manchester: Manchester Metropolitan University

Okonjo-Iweala (2005). ck $\quad c k 48$.

Ojo, O.J.B. (1987). Military Rule, Democracy and the Post-Military State, Bck $\quad c k \quad c k \quad L \quad c k$ $\quad c k \quad c k \quad c k \quad$ In: S. E. Oyovbaire. ed., Benin-city: Omega Publishers Limited. 150.

Olurode, L. (2005). Corruption As A Social Problem, Olurode, L. and R. Anifowose. eds. 2005.

The Faculty of Social Sciences, University of Lagos. 7.

Ruccio, D. F. (2008) $\quad c k c k c k \quad c k \quad c k c k \quad$ London: Routledge: Taylor and Francis. 25.

Sheffrin, S. M. (2003). $\quad$ ck . New Jersey, Upper Saddle River: Pearson Prentice Hall. 472.

Thomas and Bromley, R. (2000) 'City-centre Revitalisation: Problems of Fragmentation and Fear in the Evening and Night-time Economy', $\quad P \quad c k \quad, 1403-29$

Upreti, P. (2015) Factors affecting economic growth in developing countries, $\quad c k c k \quad P \quad$. Vol. 17, USA: University of Northern lowa. 37-54.

World Bank (2012). World Bank Reports. Retrieved from; http://search.worldbank.org/all?qterm=South+Korea\&title=\&filetype= accessed on 11 July 2013 